\title{
Assessment on the Precision of the Orthodontic Bracket Slot Dimensions Using Micro-computed Tomography (Micro-CT)
}

\author{
Nasser D Alqahtani
}

\begin{abstract}
Aim: To evaluate the precision of the orthodontic bracket slot dimensions of 0.022 inch and to compare them with those of the manufacturers' specifications.

Materials and methods: The slots of upper-right central incisor brackets $(n=5)$ from 11 commercial bracket systems of three different manufacturers (3M Unitek: Victory Mini Metal, Clarity, SmartClip, Clarity SL; ORMCO/SYBRON: Mini Diamond Twin, Damon Q, Damon Clear; Dentsply/GAC: Ovation, Mystique, In-Ovation R, In-Ovation C) were measured. The orthodontic brackets were scanned using micro-computed tomography (micro-CT), and the bracket slots were measured using micro-CT images. The slot was measured at four different surfaces (occlusal, gingival, base, and face) for both mesial and distal sites. Data were subjected to ANOVA and unpaired t-tests. A $p$-value of $\leq 0.05$ was considered statistically significant.

Results: All brackets had slot dimensions that were significantly larger $(p<0.05)$ than the stated 0.022 inch. $3 \mathrm{M}$-victory were $11.99 \%$ larger (0.02509 inch) and the closest to the stated dimension and the ORM-Damon C were $24.07 \%$ larger (0.02948 inch) than the quoted slot size of 0.022 inch. Comparison between mesial and distal sides showed that $91 \%$ of the bracket slots were asymmetrical at their bases and $100 \%$ asymmetrical at their faces. All of the bracket system showed divergent walls from base to face with values ranging from 1.96 (3M-SmartClip) to $26.58 \%$ (ORM-Damon C).

Conclusion: The actual measurements of 11 bracket systems from three different manufacturers were more substantial than the manufacturers' specifications, and the walls of the slots diverged from the bracket bases in all of the tested bracket system.

Clinical significance: Orthodontic bracket slots vary significantly from that of the manufacturers' specification. The orthodontist should anticipate such shortcomings and be able to modify treatment mechanics through additional wire bending in three spatial planes.

Keywords: Micro-CT, Orthodontic bracket, Self-ligating brackets, Slot dimension.

The Journal of Contemporary Dental Practice (2021): 10.5005/jp-journals-10024-3047
\end{abstract}

\section{INTRODUCTION}

Researchers have assessed the dimensions and precision with which medical devices are made and have thus confirmed that variations do occur in all industrial processes. The machining techniques itself are prone for several irregularities. Injection molding, for example, appears to have more rounded corners than precision grinding and machining techniques. ${ }^{1}$ In clinical orthodontics, the straight-wire technique allows clinicians to move teeth in three dimensions using only straight wires. ${ }^{2-4}$ This is accomplished by the tooth moving forces that are produced as a result of the intimate fit between archwire and the bracket slot. ${ }^{5}$ This said any discrepancy between the archwire and the bracket slot would result in an inadequate transfer of forces to the tooth and supporting tissues. Furthermore, any variations in orthodontic bracket slot profile have an impact on torque play and third-order torque expression. ${ }^{2,6}$ Thus it is of concern to orthodontists to know bracket slot accuracy and the several methods used in the production of such orthodontic brackets.

Clinicians usually assume that the manufacturers correctly specify the dimensions of the brackets and wires. Studies, however, have demonstrated dimensional discrepancies in brackets and archwires, often leading to excessive torsional play. ${ }^{5,7,8}$ As a result, torque, especially in the incisors in extraction cases, is inadequately controlled, thereby compromising the clinical outcomes. ${ }^{3}$ Previous studies comparing the precision of the orthodontic bracket slots have shown results that are against the manufacturer's specification. ${ }^{3,5,7-12}$
Department of Pediatric Dentistry and Orthodontic, College of Dentistry, King Saud University, Riyadh, Kingdom of Saudi Arabia

Corresponding Author: Nasser D Alqahtani, Department of Pediatric Dentistry and Orthodontic, College of Dentistry, King Saud University, Riyadh, Kingdom of Saudi Arabia

How to cite this article: Alqahtani ND. Assessment on the Precision of the Orthodontic Bracket Slot Dimensions Using Micro-computed Tomography (Micro-CT). J Contemp Dent Pract 2021;22(1):27-33.

Source of support: Nil

Conflict of interest: None

Digital methods have been incorporated into dental practice due to their precision, usability, and flexibility in gathering information regarding dental therapies for the diagnosis, treatment planning, fabrication of prosthesis and appliances, and for research purposes. ${ }^{13}$ Previous studies have used several devices and methods to measure slot dimensions. These include precision pin gauges, ${ }^{10}$ single-axis Maxtascan 100, ${ }^{5}$ scanning electron microscopy, microhardness tester equipped with an automatic reading system, ${ }^{14}$ and stereomicroscope. ${ }^{3}$

In recent years, the applications of micro-CT system for research purpose have been profoundly increasing. The system is equipped with high-resolution detectors, which allow projections to be rotated through multiple viewing directions to produce 3D sample images. The imaging procedure is non-destructive, and thus 
the internal characteristics of the same sample can be examined several times and remains accessible after scanning for mechanical testing. ${ }^{15}$ Furthermore, the exponential increase in the image resolution provided by the micro-CT systems facilitates accurate viewing or measurements of the samples. ${ }^{16,17}$

Consequently, the present study aimed to evaluate the precision of the conventional, ceramic, and self-ligating orthodontic bracket's slot dimension of 0.022 inch and compared them with those of the manufacturers' specification using micro-CT system. Furthermore, the precision of the slot dimension between mesial and distal sites was compared, and the parallelism of the bracket slot was determined.

\section{Materials and Methods}

The slots of five upper-right central incisor brackets (conventional, ceramic, and self-ligating brackets) from 11 commercially available bracket systems of three different manufacturers (3M Unitek: Victory Mini Metal, Clarity, SmartClip, Clarity SL; ORMCO/SYBRON: Mini Diamond Twin, Damon Q, Damon Clear; Dentsply/GAC: Ovation, Mystique, In-Ovation R, In-Ovation C) were measured in 0.022-inch dimension using micro-CT $(N=55)$. The study was conducted at College of Dentistry Research Centre (CDRC), King Saud University. The details of the bracket system used in this study are presented in Table 1.

\section{Micro-computed Tomography ( $\mu$-CT) Scanning of Brackets}

The orthodontic bracket slot was scanned with $\mu \mathrm{CT}$ (Skyscan 1172, Bruker micro-CT, Kontich, Belgium), a compact, desktop X-ray system for non-destructive 3D sample reconstruction with a high spatial resolution. The instrument acquires transmission images using a fully distortion-corrected $11 \mathrm{Mp}$ X-ray camera based on charge-coupled device (CCD) fiber-optic camera coupled to a scintillator. The acquired cross-section images are reconstructed into 3D models for further analysis. The $\mu$-CT was operated at $100 \mathrm{kV}$ and $50 \mu \mathrm{A}$ under standard resolution with $360^{\circ}$ rotations of the projections around the vertical axis and a camera exposure time of $1700 \mathrm{~ms}$. The X-rays were filtered with a 1-mm-thick aluminum filter for the variations in the sensitivity of polychromatic radiations. The acquired images were later saved as TIFF images.

The measurement of the bracket slots was performed on the saved TIFF images using Data Viewer (V.1.5.0.0, Bruker micro-CT,

Table 1: Bracket systems investigated in the study

\begin{tabular}{lll}
\hline Manufacturer & Brand & Catalogue no. \\
\hline 3M Unitek & Victory Series Mini-Metal & 3 017-547 ROTH \\
Monrovia, & Clarity & $6400-122$ ROTH \\
California, USA & Smart Clip & 3 004-142 ROTH \\
& Clarity SL & $3007-135$ ROTH \\
ORMCO/ & Mini-Diamond Twin & $351-0130$ \\
SYBRON & Damon Q & DM-Q 5-Standard Torque \\
Orange, & Damon Clear & DM-Clear 5-Standard \\
California, USA & & Torque \\
Dentsply/GAC & Ovation & 82-112-00 \\
Bohemia, New & Mystique & KIT 110-532-11 \\
York, USA & In-Ovation R & KIT 89-055-22 \\
& In-Ovation C & KIT 100-532-00 \\
\hline
\end{tabular}

Kontich, Belgium) software equipped with the $\mu$-CT. The slot was measured at four different surfaces (occlusal, gingival, base, and face) for both mesial and distal sites as shown in Figure 1. If a metal slot was inserted into a bracket base of another material, then only the metal slot insert was measured. The height between the slot walls was determined and compared with the dimensions stated by the respective manufacturers. The bracket slot divergence was determined by the difference in slot wall height from base to face.

\section{Statistical Analysis}

Statistical Package for Social Sciences [SPSS] for Windows, Version 22.0 (IBM SPSS Inc., Chicago, USA) was used to perform statistical analysis. Descriptive analysis of all the explanatory parameters was performed using mean and standard deviation for different brands and manufacturers. One-way ANOVA test followed by Tukey's posthoc analysis was used to compare the mean slot dimension in the base and face area on both mesial and distal sites and also to compare the mean percentage difference in slot dimensions between various brands of brackets under different manufacturers. Student paired " $t$ "-test was used to compare the mean mesial and distal slot dimensions of base and face area of the brackets to evaluate slot symmetry. The level of significance was set at $p \leq 0.05$.

The measurement of 35 bracket slot $\mu$-CT images was repeated two weeks later and the reliability of the measurements was analyzed using intraclass correlation coefficient (ICC). An ICC values ranging from 0.75 to 0.90 were observed that indicated good reliability of the repeated measurements.

\section{Results}

The sagittal view of the $\mu$-CT images of the maxillary right central incisors brackets used for measurements is presented in Figure 2.

The slot dimensions measured at four surfaces (occlusal, gingival, base, and face) of the bracket systems at mesial and distal sites are presented in Tables 2 and 3, respectively. Slot dimension at occlusal surface of the bracket ranged from 0.018 to 0.048 inch and 0.018 to 0.049 inch at the mesial and distal sites, respectively. The slot dimensions at gingival surface of the bracket ranged from

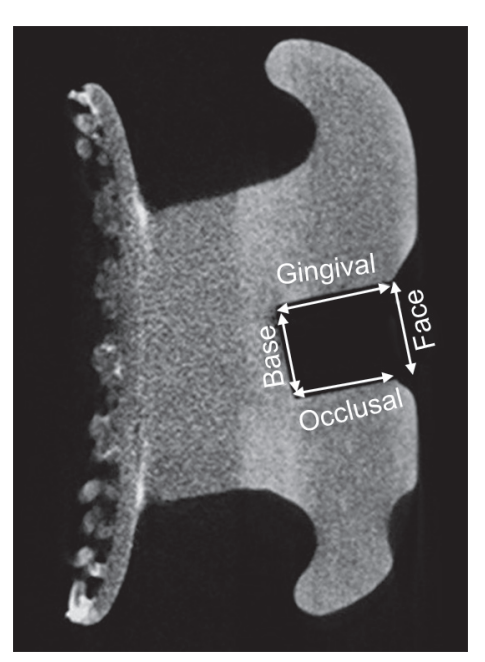

Fig. 1: Cross-sectional view of a metal bracket demonstrating the measurement surfaces 

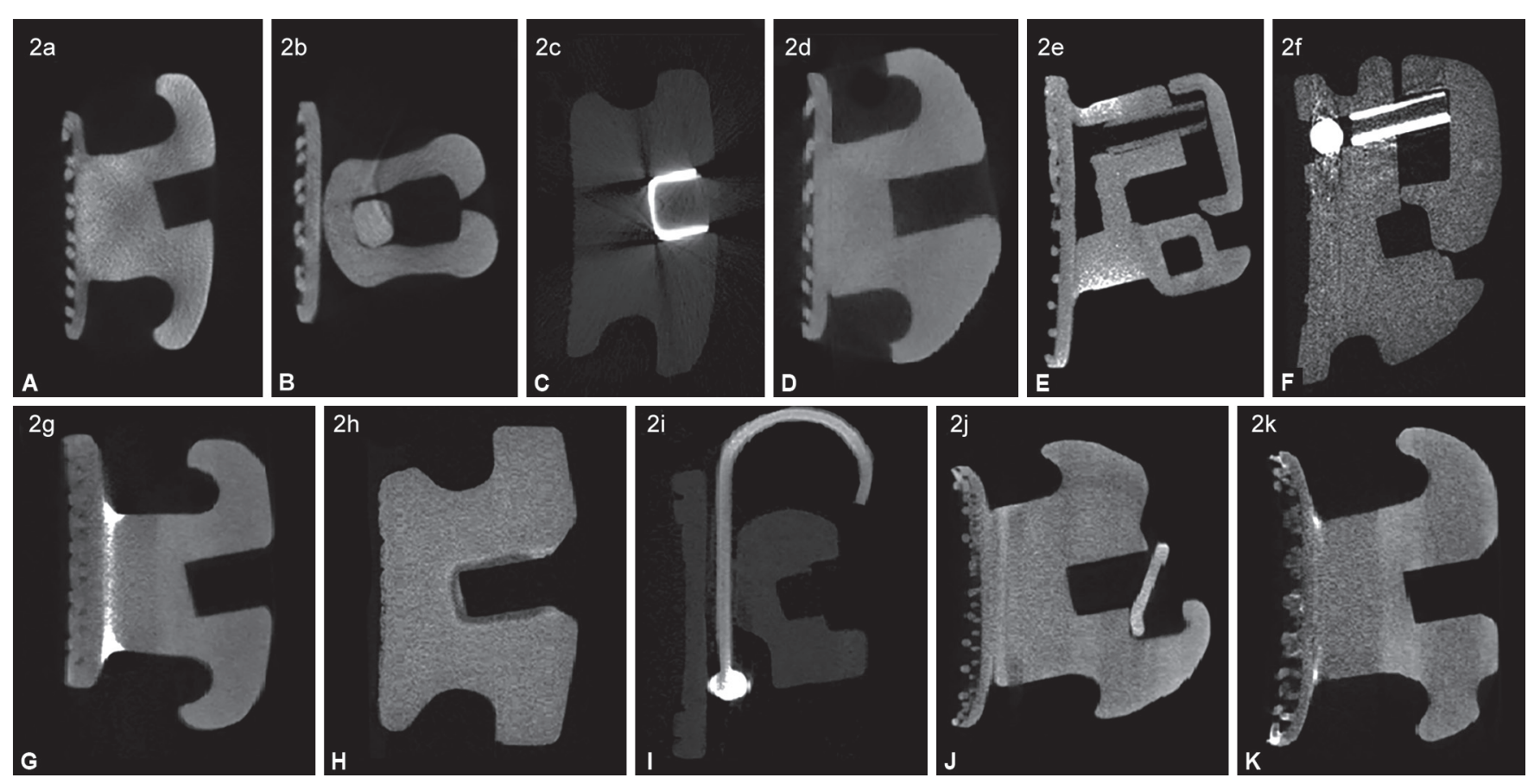

Figs. 2 A to K: Cross-sectional view of the different maxillary right central incisor brackets: (A) 3M-Victory, (B) 3M-SmartClip, (C) 3M-Clarity SL, (D) 3M-Clarity, (E) ORM-Damon, (F) ORM-Damon C, (G) ORM-Diamond, (H) GAC-Mystique, (I) GAC-In-Ova C, (J) GAC-In-Ova R, (K) GAC-Ovation

Table 2: Mean slot dimensions of the brackets in $1 / 1000^{\text {th }}$ inch (Mesial site)

\begin{tabular}{|c|c|c|c|c|c|c|c|c|}
\hline \multirow[b]{2}{*}{ Bracket system } & \multicolumn{2}{|c|}{ Occlusal } & \multicolumn{2}{|c|}{ Gingival } & \multicolumn{2}{|c|}{ Base } & \multicolumn{2}{|c|}{ Face } \\
\hline & Mean & $S D$ & Mean & $S D$ & Mean & $S D$ & Mean & $S D$ \\
\hline 3M-Victory & 23.66 & 1.01 & 32.16 & 1.23 & 24.81 & 0.28 & 24.81 & 0.28 \\
\hline 3M-Clarity & 27.90 & 0.90 & 28.35 & 0.70 & 23.13 & 0.33 & 26.87 & 0.34 \\
\hline 3M-SmartClip & 47.50 & 1.29 & 48.15 & 0.55 & 24.97 & 0.01 & 25.62 & 0.74 \\
\hline 3M-Clarity SL & 29.15 & 0.86 & 29.15 & 0.24 & 24.56 & 1.42 & 27.02 & 1.09 \\
\hline ORM-Diamond & 25.74 & 1.28 & 33.05 & 0.67 & 25.40 & 0.39 & 25.97 & 0.19 \\
\hline ORM-Damon Q & 33.11 & 1.60 & 35.27 & 1.09 & 25.63 & 0.19 & 26.53 & 0.58 \\
\hline ORM-Damon C & 48.88 & 1.37 & 66.09 & 1.22 & 25.63 & 0.19 & 33.04 & 0.01 \\
\hline GAC-Ovation & 30.96 & 0.34 & 30.53 & 0.48 & 25.85 & 0.01 & 26.76 & 0.19 \\
\hline GAC-Mystique & 36.90 & 0.81 & 39.14 & 0.89 & 25.23 & 0.40 & 26.41 & 0.40 \\
\hline GAC-In-Ova R & 22.57 & 0.39 & 38.10 & 0.58 & 25.63 & 0.19 & 26.76 & 0.39 \\
\hline GAC-In-Ova C & 18.36 & 0.30 & 34.81 & 1.09 & 24.72 & 0.78 & 25.97 & 0.39 \\
\hline
\end{tabular}

Table 3: Mean slot dimensions of the brackets in $1 / 1000^{\text {th }}$ inch (Distal site)

\begin{tabular}{|c|c|c|c|c|c|c|c|c|}
\hline \multirow[b]{2}{*}{ Bracket system } & \multicolumn{2}{|c|}{ Occlusal } & \multicolumn{2}{|c|}{ Gingival } & \multicolumn{2}{|c|}{ Base } & \multicolumn{2}{|c|}{ Face } \\
\hline & Mean & $S D$ & Mean & $S D$ & Mean & $S D$ & Mean & $S D$ \\
\hline 3M-Victory & 24.97 & 0.49 & 33.30 & 0.49 & 24.81 & 0.28 & 25.79 & 0.74 \\
\hline 3M-Clarity & 28.24 & 0.90 & 28.92 & 0.90 & 23.59 & 0.51 & 26.99 & 0.70 \\
\hline 3M-SmartClip & 48.81 & 0.74 & 48.97 & 0.01 & 24.81 & 0.28 & 25.13 & 1.13 \\
\hline 3M-Clarity SL & 29.15 & 2.48 & 30.14 & 0.73 & 23.89 & 1.18 & 27.35 & 1.18 \\
\hline ORM-Diamond & 25.63 & 1.37 & 32.78 & 0.78 & 25.63 & 0.19 & 26.08 & 0.19 \\
\hline ORM-Damon Q & 32.43 & 2.46 & 41.05 & 9.82 & 25.40 & 0.19 & 28.46 & 3.94 \\
\hline ORM-Damon C & 49.90 & 3.30 & 67.25 & 1.87 & 26.42 & 0.19 & 32.89 & 0.19 \\
\hline GAC-Ovation & 27.56 & 0.90 & 32.32 & 0.68 & 26.31 & 0.19 & 26.65 & 0.19 \\
\hline GAC-Mystique & 37.02 & 1.94 & 39.38 & 1.94 & 24.87 & 0.20 & 26.53 & 0.35 \\
\hline GAC-In-Ova R & 21.43 & 1.18 & 37.65 & 0.19 & 26.76 & 0.78 & 26.87 & 0.01 \\
\hline GAC-In-Ova C & 18.60 & 0.52 & 34.36 & 0.89 & 25.40 & 0.39 & 25.29 & 2.18 \\
\hline
\end{tabular}


Table 4: Comparison of the mean mesial and distal slot dimensions (in $1 / 1000^{\text {th }}$ inch) of base and face surface of the brackets

\begin{tabular}{|c|c|c|c|c|c|c|}
\hline \multirow[b]{2}{*}{ Bracket system } & \multirow[b]{2}{*}{ Surface } & \multicolumn{2}{|c|}{ Mesial } & \multicolumn{2}{|c|}{ Distal } & \multirow[b]{2}{*}{$p$-value } \\
\hline & & Mean & $S D$ & Mean & $S D$ & \\
\hline \multirow[t]{2}{*}{ 3M-Victory } & Base & 24.812 & 0.284 & 24.812 & 0.284 & 1.00 \\
\hline & Face & 24.975 & 0.490 & 25.793 & 0.748 & $0.04^{*}$ \\
\hline \multirow[t]{2}{*}{ 3M-Clarity } & Base & 24.976 & 0.000 & 24.812 & 0.284 & 0.42 \\
\hline & Face & 26.879 & 0.341 & 26.995 & 0.709 & 0.74 \\
\hline \multirow[t]{2}{*}{ 3M-SmartClip } & Base & 23.138 & 0.339 & 23.591 & 0.519 & 0.42 \\
\hline & Face & 25.629 & 0.748 & 25.138 & 1.132 & 0.23 \\
\hline \multirow[t]{2}{*}{ 3M-Clarity SL } & Base & 24.560 & 1.421 & 23.892 & 1.185 & 0.50 \\
\hline & Face & 27.028 & 1.009 & 27.357 & 1.182 & 0.18 \\
\hline \multirow[t]{2}{*}{ ORM-Diamond } & Base & 25.404 & 0.393 & 25.633 & 0.195 & 0.53 \\
\hline & Face & 25.972 & 0.198 & 26.087 & 0.198 & 0.42 \\
\hline \multirow[t]{2}{*}{ ORM-Damon Q } & Base & 25.633 & 0.195 & 25.406 & 0.198 & 0.42 \\
\hline & Face & 26.538 & 0.589 & 28.467 & 3.944 & 0.46 \\
\hline \multirow[t]{2}{*}{ ORM-Damon C } & Base & 25.633 & 0.521 & 26.427 & 0.195 & 0.19 \\
\hline & Face & 33.004 & 0.000 & 32.891 & 0.195 & 0.42 \\
\hline \multirow[t]{2}{*}{ GAC-Ovation } & Base & 25.858 & 0.000 & 26.314 & 0.195 & 0.06 \\
\hline & Face & 26.765 & 0.195 & 26.652 & 0.195 & 0.42 \\
\hline \multirow[t]{2}{*}{ GAC-Mystique } & Base & 25.232 & 0.409 & 24.878 & 0.205 & 0.23 \\
\hline & Face & 26.413 & 0.409 & 26.532 & 0.354 & 0.74 \\
\hline \multirow[t]{2}{*}{ GAC-In-Ova R } & Base & 25.633 & 0.195 & 26.766 & 0.786 & 0.18 \\
\hline & Face & 26.766 & 0.393 & 26.878 & 0.000 & 0.67 \\
\hline \multirow[t]{2}{*}{ GAC-In-Ova C } & Base & 24.726 & 0.782 & 25.404 & 0.393 & 0.42 \\
\hline & Face & 25.974 & 0.393 & 25.293 & 2.186 & 0.58 \\
\hline
\end{tabular}

*Statistically significant (student paired " $t$ " test)

0.028 to 0.066 inch and 0.028 to 0.067 inch at the mesial and distal sites, respectively.

Similarly, slot dimension at base of the bracket ranged from 0.023 to 0.025 inch and 0.023 to 0.026 inch at the mesial and distal sites, respectively. Similarly, the slot dimensions at face of the bracket ranged from 0.024 to 0.033 inch and 0.025 to 0.032 inch at the mesial and distal sites, respectively.

In evaluating the bracket symmetry, a comparison between mesial and distal sites was done using student paired " $t$ "-test (Table 4). The data analysis revealed difference in measurements at mesial and distal sites for both base and face surfaces of the tested bracket systems. However, the difference in measurements was not significant $(p>0.05)$ except for $3 \mathrm{M}$-Victory, which showed a significant difference in the face measurements from mesial to distal site $(p=0.04)$. On the contrary, the measurement of the base surface for the 3M-Victory bracket system at mesial and distal surfaces was accurate $(p=1.00)$. It was shown that $91 \%$ of the bracket slots were asymmetrical at their bases against $100 \%$ at their faces.

Table 5 presents the mean difference in the bracket slot height against the manufacturer stated height of 0.022 inch. Irrespective of the bracket system and manufacturer, ORM-Damon $C$ showed the highest difference in bracket slot height at both mesial (7.24) and distal (7.58) sites. The lowest difference in bracket slot height was seen with $3 \mathrm{M}$-Victory at both mesial (2.81) and distal (3.22) sites.

The mean difference in the bracket slot height among different bracket systems under same manufacturers showed significant differences for ORM and GAC. On the contrary, bracket systems under $3 \mathrm{M}$ did not show any significant mean difference $(p=0.41$ and 0.73 for mesial and distal sites, respectively).
Table 5: Mean difference in the bracket slot height compared against the manufacturer stated height of 0.022 inch

\begin{tabular}{lcc}
\hline & \multicolumn{2}{c}{ Mean difference (1/1000th inch) } \\
\cline { 2 - 3 } Bracket systems & Mesial & Distal \\
\hline 3M-Victory & 2.81 & 3.22 \\
3M-Clarity & 2.93 & 3.21 \\
3M-SmartClip & 3.22 & 2.90 \\
3M-Clarity SL & 3.71 & 3.54 \\
p-value & 0.41 & 0.73 \\
ORM-Diamond & 3.61 & 3.78 \\
ORM-Damon Q & 4.01 & 4.86 \\
ORM-Damon C & 7.24 & 7.58 \\
p-value & $<0.001^{*}$ & $0.02^{*}$ \\
GAC-Ovation & 4.23 & 4.40 \\
GAC-Mystique & 3.74 & 3.62 \\
GAC-In-Ova R & 4.12 & 4.74 \\
GAC-In-Ova C & 3.27 & 3.27 \\
p-value & $0.02^{*}$ & $0.03^{*}$ \\
\hline
\end{tabular}

*Statistically significant (Tukey's post-hoc analysis)

The mean percentage difference in bracket slot height against the manufacturer stated height of 0.022 inch is presented in Fig. 3. $3 \mathrm{M}$-Victory was $11.99 \%$ larger (0.02509 inch) and the closest to the stated dimension and the ORM-Damon C were $24.07 \%$ larger (0.02948 inch) than the quoted slot size of 0.022 inch. Among the manufacturers, $3 \mathrm{M}$ bracket systems showed least variations in bracket slot height compared to the manufacturer's stated dimension of 0.022 inch.

Figure 4 presents the mean bracket slot height at base and face, and the mean percentage of slot divergence from base to face. 3M-SmartClip showed non-significant and least difference in bracket slot height from base to face and the mean divergence was $1.96 \%$. On the contrary, ORM-Damon C showed highly significant difference in bracket slot height from base to face and accordingly the bracket slot divergence was $26.58 \%$, which was also the most divergent among the tested bracket system.

\section{Discussion}

Up to the authors' knowledge, this is the first study to utilize the micro-CT in evaluating the precision of the slot size of conventional, ceramic, and self-ligating brackets from different manufacturers. The use of micro-CT facilitates enhanced precision of the orthodontic bracket slot measurement compared to other measurement techniques, such as stereomicroscope, ${ }^{3,7}$ Maxtascan, ${ }^{5}$ scanning electron microscopy (SEM) ${ }^{18}$ microhardness tester, ${ }^{14}$ and digital gauges ${ }^{19}$ as used in previous studies. The outcome of the current study agree with those of the previous studies that have demonstrated significantly greater bracket slot sizes compared to that of manufacturers specification. . $^{3,5,7-12}$

The outcome of the current study demonstrated that all the study brackets were significantly greater than the manufacturers' stated dimension of 0.022 inch, and the walls of the bracket slot diverged from the base in all of the bracket systems. The study also demonstrated that discrepancies exist not only between different manufacturers but also in the bracket systems from the same manufacturer. Similar such outcome has been reported earlier by different authors evaluating the bracket slot measurements. 


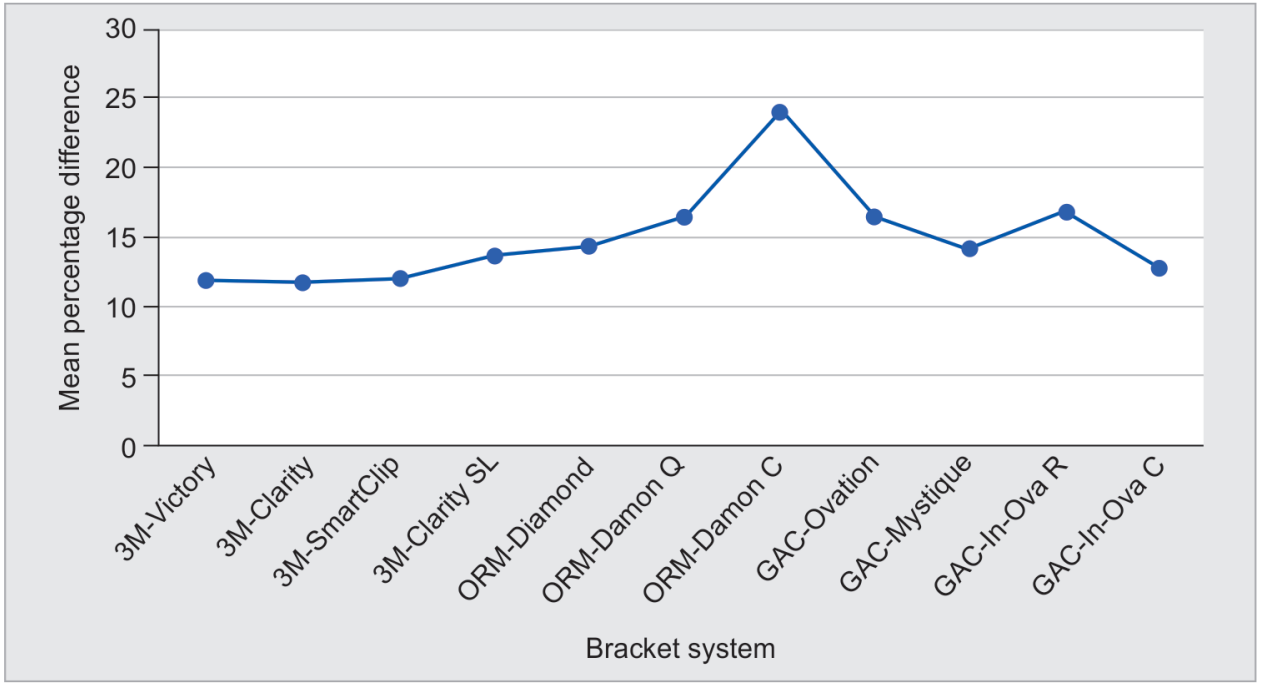

Fig. 3: Mean percentage difference between the measured bracket slot heights of the tested bracket system against manufacturer's stated height of 0.022 inch

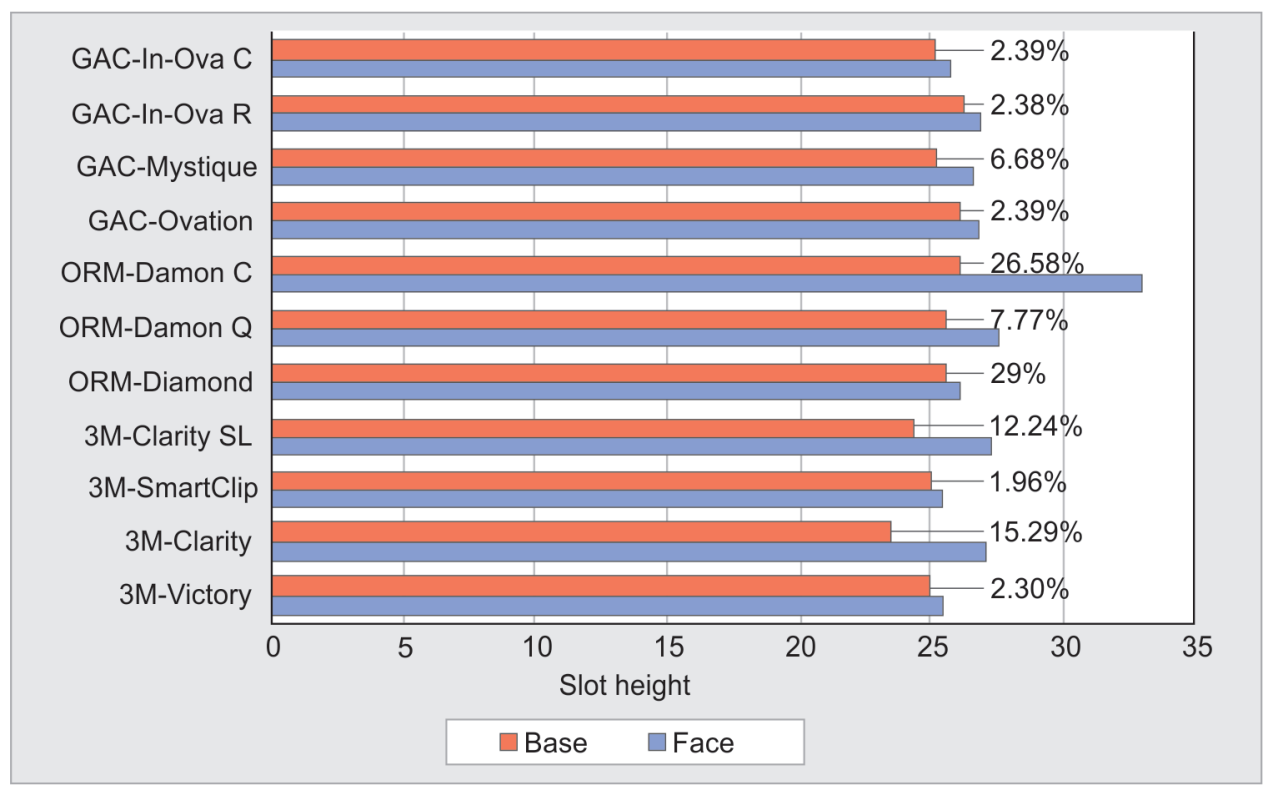

Fig. 3: Mean bracket slot height at base and face of the tested bracket system. The number indicates the percentage of slot divergence from base to face

Kusy and Whitley ${ }^{12}$ analyzed 24 brackets using critical contact angle from eight manufacturers and found three smaller bracket slots, and another 20 wider than their manufacturers' stated measurements. The slot of 0.018 inch bracket was $16 \%$ bigger and the slot of 0.022 inch brackets was $8 \%$ wider than manufacturer specification. Similarly, Cash et al. ${ }^{5}$ found a wider bracket slot ranging from 5 to $24 \%$ compared to manufacturer's specification in all of the 11 commercially available bracket systems using Maxtascan 100 manual measuring device. Also, the study confirmed that the geometry of bracket slots variations, with some bracket systems, exhibits parallel, divergent, or convergent walls. Demling et al. ${ }^{9}$ using precision pin gauges compared the accuracy of slot dimensions of three lingual bracket systems, and they found that the brackets exhibited significant differences in slot dimension that could clinically result in torque play.

The electron microscopic measurements of upper central incisor self-ligating brackets from six manufacturers reported by Bhalla et al. ${ }^{7}$ were larger than the manufacturers' stated dimension, and the walls of the slots diverged from the bracket bases. Moreover, Brown et al. ${ }^{14}$ used microhardness tester to evaluate the slot size of an entire series of metal orthodontic brackets. The authors found that the slot dimension differed greatly from series to series as well as within the series. Furthermore, Lee et al. ${ }^{3}$ evaluating the dimensional accuracies of ceramic self-ligation brackets using stereomicroscope found a significantly wider slot tops compared to slot bases thus creating a divergent slot profile. 
In the present study, the mesial and distal sites were compared to assess the symmetry of the brackets and surprisingly all of the bracket systems showed asymmetry. Although the dimensions varied from mesial to distal sites, the difference was not significant. All of the tested bracket system slots were asymmetrical at face from mesial to distal sites, whereas $91 \%$ of the brackets showed asymmetry at base from mesial to distal sites. This was in accordance with the findings of the previous study by Lefebvre et al. ${ }^{20}$ where the authors compared the mesial and distal sites and found a significantly asymmetrical bracket slots in $45 \%$ of the tested brackets. Contrary to the findings of our study, Khan et al. ${ }^{19}$ demonstrated uniformity of the bracket slot heights on both mesial and distal sites with all of the tested brackets using digital gauges. However, the authors reported an increased slot heights ranging from 6 to $19 \%$ in most of the commercially available bracket series.

While most manufactures may not specify their technical tolerances for bracket slot differences, manufacturing inaccuracies may occur as a consequence of any flaws or defects in manufacturing processes or material type. ${ }^{8,21}$ Orthodontic brackets cast from molds are affected by shrinkage and milling, which introduces various defects such as grooves and striations displaying porosity in the slot walls. To overcome such manufacturing defects and ensure that the defects do not interfere with the presence of archwire, manufacturers consciously increase the slot dimensions and bevel the edge of archwires. ${ }^{12}$ Furthermore, it has been claimed that European orthodontic bracket manufacturers are using metric tooling and, as a result of the disparity between this and American imperial-based tooling, the 0.022 -inch slots in European-made brackets are immediately over-sized by $4.22 \%$ even before any manufacturing variation is identified. ${ }^{11}$

It is always necessary that orthodontist be aware that the pre-adjusted bracket and wire systems that are commonly used in clinical practice cannot provide the three-dimensional control necessary for a satisfactory treatment outcome. ${ }^{5}$ One should anticipate and be able to modify treatment mechanics through additional wire bending in three spatial planes to overcome any bracket shortcomings. ${ }^{14}$ Furthermore, standardizations of the orthodontic brackets slot dimensions among the manufacturers and publishing of the actual torque play would be beneficial.

The material type affecting the torquing moment has been demonstrated in a study by Morina et al. ${ }^{22}$ The authors found a high torquing moment with ceramic brackets. In contrast, self-ligating, polycarbonate, and metallic brackets demonstrated almost a sevenfold decreased moment and a $100 \%$ increase in torque loss when a $0.019 \times 0.022$ inch stainless steel wire was inserted into a 0.022-inch bracket slot. However, in the present study, the torsional play of the archwire and bracket slot was not evaluated and is considered as a short coming of the study.

\section{Conclusion}

There was a considerable variation in the slot sizes between orthodontic bracket systems from different manufacturers and between different bracket systems from the same manufacturer. $3 \mathrm{M}$-Victory were $11.99 \%$ larger (0.02509 inch) and the closest to the stated dimension and the ORM-Damon C were $24.07 \%$ larger (0.02948 inch) than the specified slot size of 0.022 inch. The walls of the bracket slots were divergent (1.96-26.58\%) from the base for all of the tested bracket system.

\section{ACKnowledgment}

The author would like to express their deep appreciation and gratitude [blinded for peer review] support and guidance throughout the study.

\section{References}

1. Kalpakjian S, Schmid S, Sekar V. Manufacturing engineering and technology/Serope Kalpakjian, Illinois Institute of Technology, Steven R Schmid, The University of Notre Dame. 7th edition; 2013.

2. Gioka C, Eliades T. Materials-induced variation in the torque expression of preadjusted appliances. Am J Orthod Dentofacial Orthop 2004;125(3):323-328. DOI: 10.1016/j.ajodo.2003.02.007.

3. Lee Y, Lee DY, Kim YJ. Dimensional accuracy of ceramic self-ligating brackets and estimates of theoretical torsional play. Angle Orthod 2016;86(5):804-809. DOI: 10.2319/092415-647.1.

4. Urias D, Mustafa FIA. Anchorage control in bioprogressive vs straight-wire treatment. Angle Orthod 2005;75(6):987-992. DOI: 10.1043/0003-3219(2005)75[987:ACIBVS]2.0.CO;2.

5. Cash AC, Good SA, Curtis RV, et al. An evaluation of slot size in orthodontic brackets--are standards as expected? Angle Orthod 2004;74(4):450-453. DOI: 10.1043/0003-3219(2004)074<0450:AEOS $\mathrm{SI}>2.0 . \mathrm{CO} ; 2$.

6. Fischer-Brandies $\mathrm{H}$, Orthuber W, Es-Souni $\mathrm{M}$, et al.. Torque transmission between square wire and bracket as a function of measurement, form and hardness parameters. J Orofac Orthop 2000;61(4):258-265. DOI: 10.1007/s000560050011.

7. Bhalla NB, Good SA, McDonald F, et al. Assessment of slot sizes in self-ligating brackets using electron microscopy. Aust Orthod J 2010;26(1):38-41.

8. Major TW, Carey JP, Nobes DS, et al. Orthodontic bracket manufacturing tolerances and dimensional differences between select self-ligating brackets. J Dent Biomech 2010;2010:781321. DOI: 10.4061/2010/781321.

9. Demling A, Dittmer MP, Schwestka-Polly R. Comparative analysis of slot dimension in lingual bracket systems. Head Face Med 2009;5:27. DOI: 10.1186/1746-160X-5-27.

10. Meling TR, Odegaard J, Seqner D. On bracket slot height: a methodologic study. Am J Orthod Dentofacial Orthop 1998;113(4): 387-393. DOI: 10.1016/s0889-5406(98)80009-7.

11. Siatkowski RE. Loss of anterior torque control due to variations in bracket slot and archwire dimensions. J Clin Orthod 1999;33(9):508-510.

12. Kusy RP, Whitley JQ. Assessment of second-order clearances between orthodontic archwires and bracket slots via the critical contact angle for binding. Angle Orthod 1999;69(1):71-80. DOI: 10.1043/0003-3219(1999)069<0071:AOSOCB>2.3.CO;2.

13. Abduo J, Elseyoufi M. Accuracy of intraoral scanners: a systematic review of influencing factors. Eur J Prosthodont Restor Dent 2018;26(3):101-121. DOI: 10.1922/EJPRD_01752Abduo21.

14. Brown P, Wagner W, Choi H. Orthodontic bracket slot dimensions as measured from entire bracket series. Angle Orthod 2015;85(4):678682. DOI: $10.2319 / 042814-307.1$

15. Swain MV, Xue J. State of the art of Micro-CT applications in dental research. Int J Oral Sci 2009;1(4):177-188. DOI: 10.4248/IJOS09031.

16. Acar B, Kamburoglu K, Tatar I, et al. Comparison of microcomputerized tomography and cone-beam computerized tomography in the detection of accessory canals in primary molars. Imaging Sci Dent 2015;45(4):205-211. DOI: 10.5624/isd.2015.45. 4.205.

17. Tamminen IS, Isaksson $\mathrm{H}$, Aula AS, et al. Reproducibility and agreement of micro-CT and histomorphometry in human trabecular bone with different metabolic status. J Bone Miner Metab 2011;29(4):442-448. DOI: 10.1007/s00774-010-0236-6.

18. Dolci GS, Spohr AM, Zimmer ER, et al. Assessment of the dimensions and surface characteristics of orthodontic wires and bracket slots. Dental Press J Orthod 2013;18(2):69-75. DOI: 10.1590/s217694512013000200016. 
19. Khan T, Khan H, Mohsin S, et al. Manufacturer tolerance in mesial and distal slot height of 0.022-inch maxillary lateral incisor brackets. Pak Orthod J 2018;10(1):41-45.

20. Lefebvre C, Saadaoui H, Olive J-M, et al. Variability of slot size in orthodontic brackets. Clin Exp Dent Res 2019;5(5):528-533. DOI: $10.1002 /$ cre2.219.
21. Meling TR, Odegaard J. On the variability of cross-sectional dimensions and torsional properties of rectangular nickel-titanium arch wires. Am J Orthod Dentofacial Orthop 1998;113(5):546-557.

22. Morina E, Eliades T, Pandis N, et al. Torque expression of self-ligating brackets compared with conventional metallic, ceramic, and plastic brackets. Eur J Orthod 2008;30(3):233-238. DOI: 10.1093/ejo/cjn005. 